\title{
Optimization of an Appropriate Technology Based Process for Converting Waste Plastic in to Liquid Fuel via Thermal Decomposition
}

\author{
Daniel DeNeve ${ }^{1}$, Chandni Joshi ${ }^{1}$, Abhishek Samdani ${ }^{2}$, John Higgins ${ }^{1} \&$ Jeffrey Seay ${ }^{1}$ \\ ${ }^{1}$ Department of Chemical Engineering, University of Kentucky, United States \\ ${ }^{2}$ Indian Institute of Technology, Roorkee, India \\ Correspondence: Jeffrey Seay, Department of Chemical Engineering, University of Kentucky, United States. \\ E-mail: jeffrey.seay@uky.edu
}

Received: December 31, 2016

Accepted: January 20, 2017

Online Published: March 30, 2017

doi:10.5539/jsd.v10n2p116

URL: https://doi.org/10.5539/jsd.v10n2p116

\begin{abstract}
Municipal solid waste in the developing world is often improperly disposed of in dumps near slums or simply discarded along the roadside in rural villages. This waste, particularly plastic, is a serious environmental and health concern for the communities in those regions. Lack of infrastructure, capital, and governmental policies contributes to the waste pile-up. Thus, methods of removing, recycling, and repurposing the otherwise pollutant waste are needed. In order to address the problem of plastic waste accumulation in developing regions, a process based on the principles of Appropriate Technology for converting waste plastic into a fuel oil similar to diesel fuel or kerosene has been proposed by the University of Kentucky Appropriate Technology and Sustainability (UKATS) research team. Several commonly occurring plastics such as High and Low Density Polyethylene, Polypropylene, and Polystyrene have been analyzed for their potential as a source of hydrocarbon fuel oil. In order to optimize this chemical process, the temperature parameters leading to maximum product yield have been studied. Experiments have been conducted in a small scale pyrolysis chamber to determine the optimum process temperature. Along with data collection of individual plastics, a mixture of the waste plastic was also analyzed.
\end{abstract}

Keywords: municipal solid waste, pyrolysis, thermal decomposition, sustainability

\section{Background}

\subsection{The Global Problem of Waste Plastic}

Waste accumulation in developing countries is a major challenge. Due to population growth, urbanization, modernization, industrialization, and increased access to prepackaged goods, which leads to an increase in consumption growth, waste generation has dramatically risen around the world (Joshi and Seay, 2016). This phenomenon coupled with lack of waste management, failure of recycling technologies and governmental policies, waste has simply been discarded on trash dumps surrounding rural communities in developing countries (Joshi and Seay, 2016).

Specifically, management and recycling of plastic that is present in municipal solid waste (MSW) is a global challenge. Currently, waste plastic is the third largest contributor of MSW, amounting to $20-30 \%$ by volume and $10-12 \%$ by weight of total waste accumulation (Joshi and Seay, 2016). In 2005, generation of plastic in MSW in the United States was 26.3 million metric tons, of this only 1.5 million was recovered, with over $94 \%$ of it simply being discarded (Barnes et al., 2016). As a result, careless dumping practices in both developed and underdeveloped regions is posing a potential threat to the environment and its ecosystems, both on land and in the oceans.

Inappropriate waste management and improper human behavior lead to the release of waste plastic into the environment via transportation, wind-blown littering from landfills and contamination of waterways. This allows the plastic to eventually make its way to the oceans, where $80 \%$ of all waste is plastic (Barnes et al., 2016; Green, et al., 2015). An estimated 5.25 trillion pieces of plastic, weighing 270,000 tons have been reported to be present at sea (Joshi and Seay, 2016). Not only is this discarded plastic floating on five major gyres in the oceans, but the 
denser particles have been witnessed 6,770 meters below sea level (Barnes et al., 2016, Gross, 2013). The types of waste plastic include single use disposable bags, fishing equipment, food and beverage packaging, lighters, and similar items from urban development and tourism (Barnes et al., 2016; Gross, 2013).

As a result, the ubiquity of waste plastic on beaches, the ocean surface and on the sea bed is endangering both marine and bird life. Dependent on the location, the amount of plastic debris varies from 0 to 7290 items per hectare (Barnes, et al., 2016). Most of these items have been fragmented to a size of $2.5 \mathrm{~mm}$ or smaller, classified by researchers as micro debris, which are often times difficult to observe with the naked eye and extremely difficult to remove from the ocean environment (Barnes et al., 2016; Gross, 2013). If ingested, both small and large fragments of plastic present a physical hazard to organisms, clogging feeding appendages or the digestive system, with the potential to be taken up from the gut into other body tissues, and the chemicals used in the manufacture of plastics to be ingested as the plastic degrades (Barnes et al., 2016; Gross, 2013). Additionally, the degradation of plastic is dependent on the amount of UV light reaching the particles and the abundance of oxygen. Therefore, as plastic sinks deeper into the ocean, the time taken to degrade is increased from hundreds to thousands of years (Barnes et al.; 2016; Gross, 2013; Green, et al., 2015), further augmenting the negative consequences on marine life.

Most of the plastic that enters the ocean consists of single use items, like low density polyethylene, linear low-density polyethylene and high density polyethylene carrier bags (Barnes et al., 2016; Green, et al.; 2015). As these bags float and cover the seabed, research has proven that they are depleting organic matter, reducing the amount of chlorophyll generated by biomass producing organisms and altering physicochemical characteristics associated with nutrient cycling. The same consequences have been reported for compostable or biodegradable bags (Gross, 2013; Green, et al., 2015). Consequently, this alteration in ecosystems is posing a physical barrier to mass and energy exchange across the sediment-water interface, driving the system to a different balance point (Green, et al., 2015). A change in the marine ecosystem will have rippling effect on the numerous species that rely on it for their livelihoods.

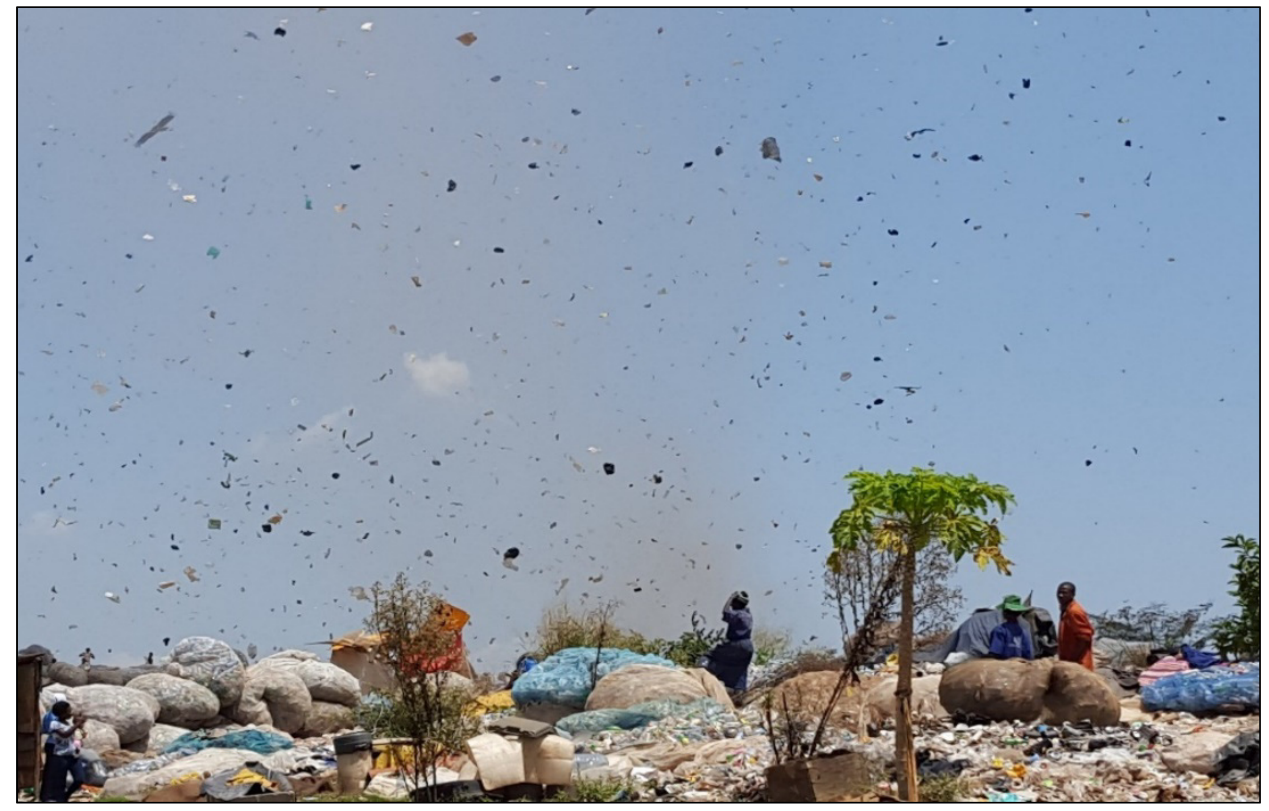

Figure 1. Trash blowing around a dump in Kampala, Uganda

However, the plastic that has been dumped in the oceans since the 1940s cannot simply be collected and removed. This effort would require an immense amount of resources and assistance from governmental policies, which are currently minimal in many countries of the world. Also, the direct removal of plastic is harmful to the marine ecosystem as organisms such as zooplankton are attached to every piece of waste plastic - removal of which will disrupt the normal flora and fauna of the oceanic ecosystems (Gross, 2013).

A solution to this grand challenge presents itself in prohibiting the waste plastic from entering the ocean initially (Barnes et al., 2016; Joshi and Seay; 2016, Gross, 2013; Green, et al., 2015). This can be accomplished by giving the plastic a value, so that instead of discarding the plastic in trash dumps and waterways, it will instead be picked up from the littered streets and utilized as a feedstock for the production of fuel oil. The goal of this effort is to keep 
the plastic from being discarded and making its way to the ocean.

\subsection{Appropriate Technology}

Different regions of the world have different technological capabilities. As a result, technical solutions must be appropriate for the intended users. This is especially important for rural or underdeveloped regions. The design philosophy of Appropriate Technology (AT) was first described by E.F. Schumacher in his book, Small is Beautiful (1973). AT has been described as being based upon "technological choices and applications that are small scale, decentralized, labor-intensive, energy efficient, environmentally sound, and locally controlled" (Hazeltine and Bull, 1999). Unlike industrial processes, AT based processes are generally intended for rural or developing communities (Joshi and Seay, 2016).

Because the problem of waste plastic accumulation is widespread, addressing it at the source is vital. Decentralized solutions based upon the principles of AT are needed to intercept waste plastic before it enters the ecosystem. This research will address the optimization of an AT based process for converting waste plastic to a liquid fuel oil, as illustrated in Figure 2. The design and operation of this AT based process, developed by the University of Kentucky Appropriate Technology and Sustainability (UKATS) research team, has been previously described (Joshi and Seay, 2016).

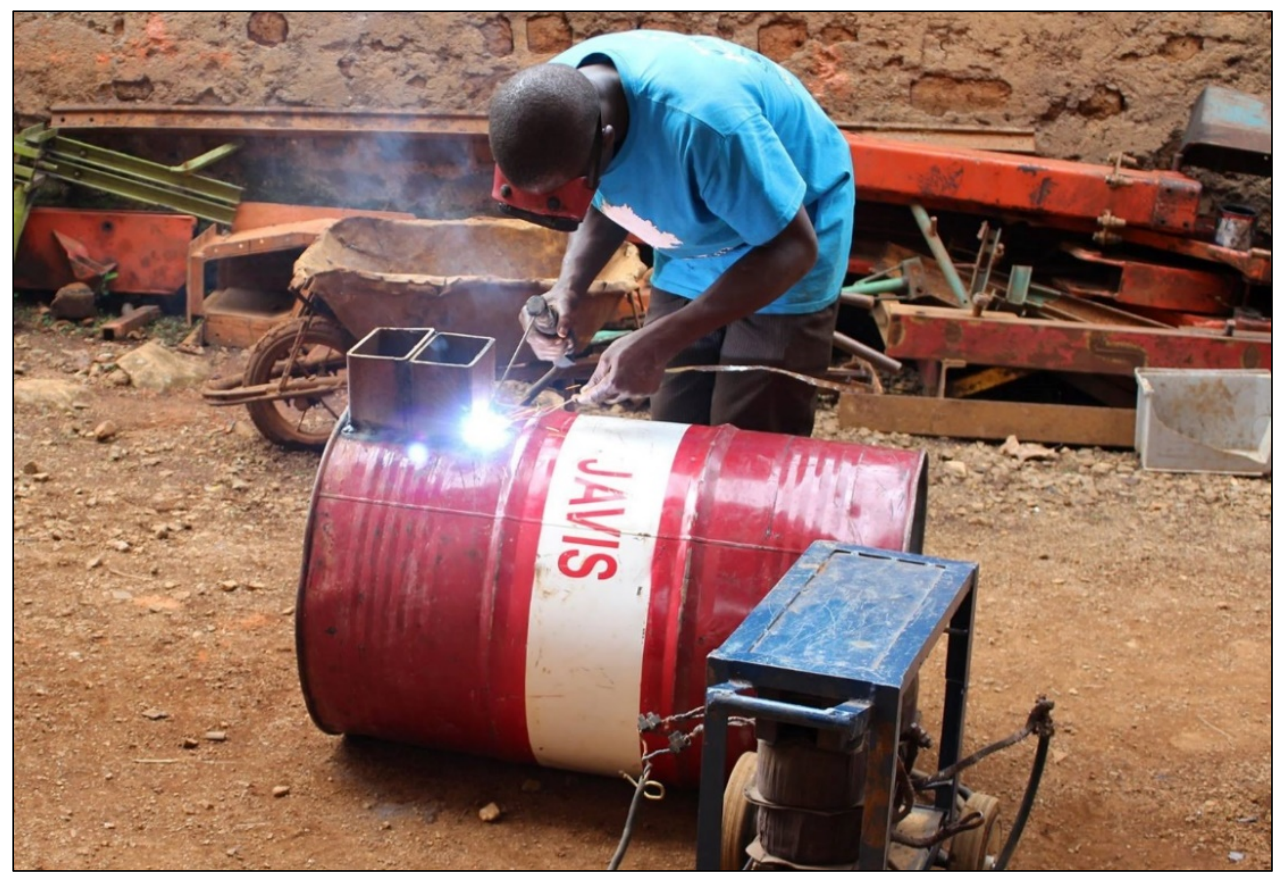

Figure 2. A technician assembles a UKATS Processor in Bangang, Cameroon

\subsection{Thermal Decomposition of Plastic}

This research will focus on the thermal decomposition of hydrocarbon plastics to produce a fuel oil similar to diesel fuel or kerosene. As previously described plastics commonly found in MSW such as High Density Polyethylene (HDPE), Low Density Polyethylene (LDPE), Polypropylene (PP), and Polystyrene (PS) are all suitable raw materials for this process (Joshi and Seay, 2016). The chemical process for converting hydrocarbon plastic in fuel oil by thermal decomposition in the absence of oxygen has been well established by previous researchers (Sarker, et al., 2012a; Sarker, et al., 2012b; Singh and Ruj, 2016; Demirbas, 2004; Pinto, et al., 1999; Al-Salem, et al., 2009; Miskolczi, et al., 2004; Wong, et al., 2015; Panda, et al., 2010). The key result of this research will be to experimentally determine the optimum operating temperature for the AT based thermal decomposition of HDPE, LDPE, PP, PS and a mixture of all four types to produce a fuel oil suitable for use in developing regions.

\section{Experimental Apparatus}

In order to determine the ideal temperature parameters for thermal decomposition of waste plastic in the UKATS Processor, a laboratory scale batch pyrolysis reactor was used. Experiments were designed to determine the temperature that optimizes the yield of fuel oil recovered from waste plastic. The pyrolysis reaction was carried 
out in a chamber constructed from steel pipe of length 30.25 inches and diameter of 1 inch. The vapor product exits the top of the reactor, is cooled in an air-cooled down-pipe and is condensed in a direct contact water bath. The liquid fuel oil product is then decanted from the water bath. A small amount of char is left behind after each batch. This char must be cleaned out before each trial. The experimental apparatus is illustrated in Figure 3.

The apparatus was heated using a LAB-TEMP Series: F-020-WI-NI-1625-6-21 laboratory clam shell electric heater. The heater, illustrated in Figure 3, surrounds the steel piping leaving 8 inches of the piping exposed at the top. The heater was controlled by dual solid state relays via a single E5CC Temperature Indicating Controller, while the heating coils were positioned at the top and bottom of clam shell. The computer taking a temperature reading from the center of the heating elements manipulated the temperature near the set point by operating in a sinusoidal curve within $\pm 5^{\circ} \mathrm{C}$ with improving precision with time. The insulation was composed of ceramic fiber and enclosed within two inches of the reactor piping. A schematic of the pyrolysis reactor and control configuration is illustrated in Figure 4.

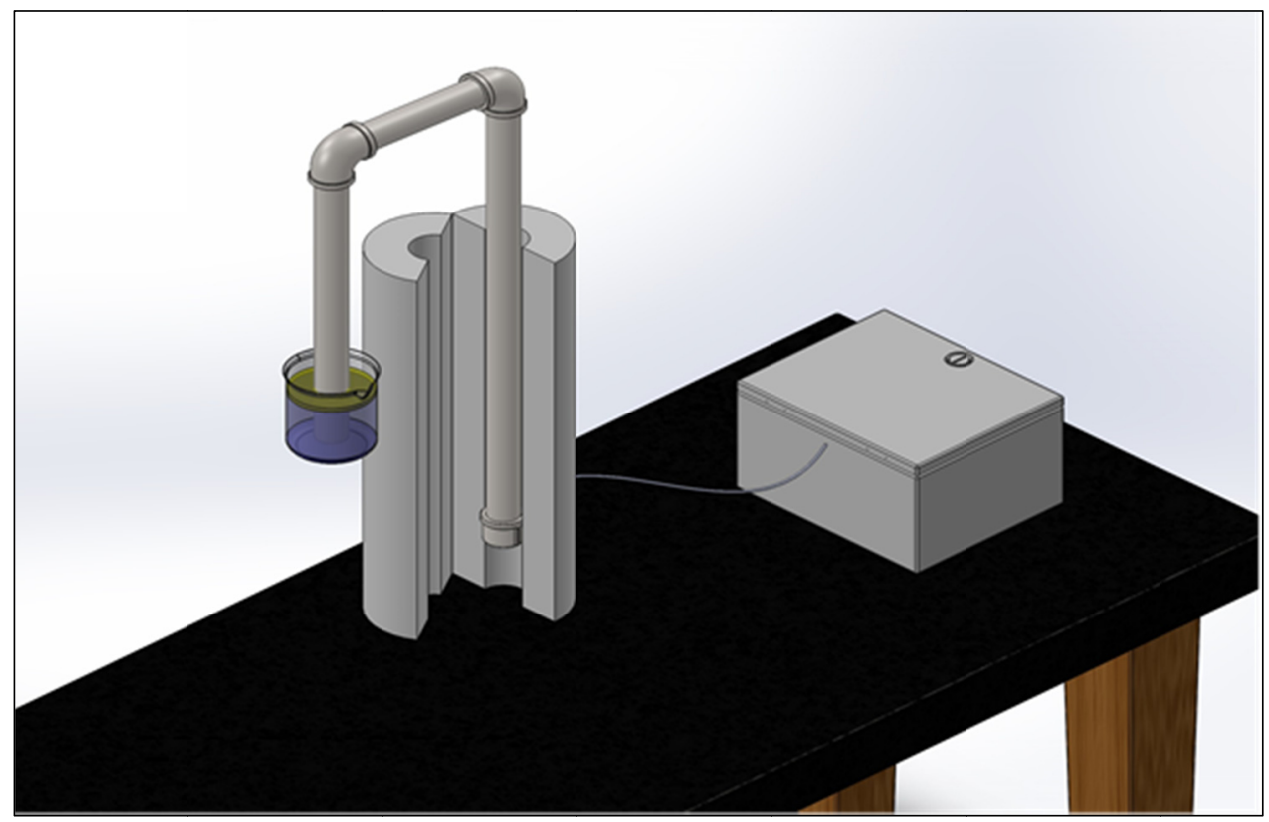

Figure 3. Laboratory pyrolysis reactor and control box

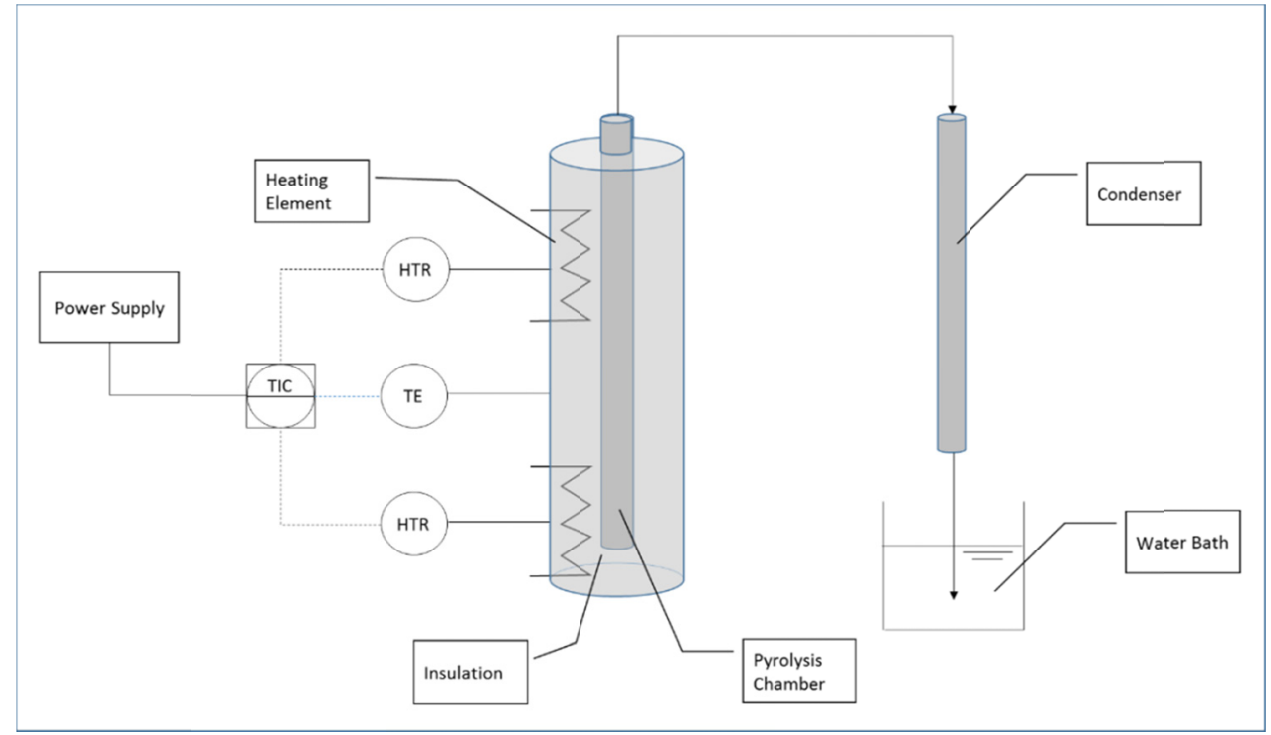

Figure 4. Control schematic of pyrolysis reactor 


\section{Experimental Method}

The process of thermal decomposition of plastic has been proven to effectively produce hydrocarbon fuel (Sarker, et al., 2012). For the batch process pyrolysis reactor, LDPE, HDPE, PP and PS were used as feedstock. HDPE came from milk containers cut into 2 to $3 \mathrm{~cm}$ strips. Both PP and LDPE pellets, having a size of 1.5 to $2 \mathrm{~mm}$, were used. The LDPE was manufactured by Dupont and the PP by Ferro Corporation. PS was crushed and cut into shards from picnic cutlery as well as disposable laboratory test tubes. Other types of plastic such as Polyethylene Terephthalate (PETE) and Poly Vinyl Chloride (PVC) were not used as unintended byproducts can be formed (Singh and Ruj, 2016).

For each experimental run, the pyrolysis reactor was filled with 75 grams of plastic. The reactor was heated at a rate of $20^{\circ} \mathrm{C} / \mathrm{min}$ until the operating temperature was reached. Experiments were conducted at operating temperatures of 450,475 , and $500^{\circ} \mathrm{C}$. Each run was carried out until the pyrolysis was complete. The reaction time varied depending on the plastic type and the operating temperature of the specific trial, but the typical run time was 4 hours from the start of heating. PP and PS typically required less time that HDPE and LDPE.

\section{Experimental Results and Analysis}

The results of the pyrolysis experiments are shown in Table 1. For each plastic type, results indicated that yield increases with increasing temperatures.

Table 1. Laboratory experimental results

\begin{tabular}{|c|c|c|c|c|c|}
\hline $\begin{array}{c}\text { Trial } \\
\text { Number }\end{array}$ & Plastic Type & Temperature $\left({ }^{\circ} \mathbf{C}\right)$ & $\begin{array}{l}\text { \% Fuel Oil Yield } \\
\text { (mass basis) }\end{array}$ & Average \% Yield & $\begin{array}{l}\text { Standard } \\
\text { Deviation }\end{array}$ \\
\hline 1 & LDPE & 450 & 55.10 & & \\
\hline 2 & LDPE & 450 & 53.47 & 53.57 & 1.21 \\
\hline 3 & LDPE & 450 & 52.13 & & \\
\hline 4 & LDPE & 475 & 67.70 & & \\
\hline 5 & LDPE & 475 & 70.40 & 69.63 & 1.38 \\
\hline 6 & LDPE & 475 & 70.80 & & \\
\hline 7 & HDPE & 475 & 67.30 & & \\
\hline 8 & HDPE & 475 & 63.62 & 66.97 & 2.62 \\
\hline 9 & HDPE & 475 & 70.00 & & \\
\hline 10 & HDPE & 450 & 57.60 & & \\
\hline 11 & HDPE & 450 & 49.87 & 53.38 & 3.20 \\
\hline 12 & HDPE & 450 & 52.67 & & \\
\hline 13 & HDPE & 500 & 84.67 & & \\
\hline 14 & HDPE & 500 & 82.00 & 86.13 & 4.10 \\
\hline 15 & HDPE & 500 & 91.73 & & \\
\hline 16 & $\mathrm{PP}$ & 450 & 72.40 & & \\
\hline 17 & PP & 450 & 78.27 & 74.44 & 2.70 \\
\hline 18 & PP & 450 & 72.67 & & \\
\hline 19 & $\mathrm{PP}$ & 475 & 78.80 & & \\
\hline 20 & PP & 475 & 82.80 & 78.31 & 3.88 \\
\hline 21 & PP & 475 & 73.33 & & \\
\hline 22 & PS & 450 & 84.80 & & \\
\hline 23 & PS & 450 & 83.47 & 84.18 & 0.55 \\
\hline 24 & PS & 450 & 84.27 & & \\
\hline 25 & PS & 475 & 89.38 & & \\
\hline 26 & PS & 475 & 91.47 & 90.06 & 1.00 \\
\hline 27 & PS & 475 & 89.33 & & \\
\hline
\end{tabular}




\begin{tabular}{llllll}
\hline 28 & Mix & 450 & 55.17 & 56.44 & 1.93 \\
29 & Mix & 450 & 59.17 & & \\
30 & Mix & 450 & 55.00 & 82.70 & 2.47 \\
31 & Mix & 475 & 86.19 & & \\
32 & Mix & 475 & 80.72 & & \\
33 & Mix & 475 & 81.20 & \\
\hline
\end{tabular}

The average percent yield along with the experimental error is illustrated in Figure 5. At temperatures at or above $450^{\circ} \mathrm{C}$ a percent yield of at least $50 \%$ was found. Temperatures below $450^{\circ} \mathrm{C}$ did not result in appropriate yields after 4 hours of operation. Typically, the length of time before the first droplet of oil appeared in the condenser was between 18 and 35 mins. Data was collected for HDPE at $500^{\circ} \mathrm{C}$ although this temperature was found to be inappropriate for the other types of plastic. Although temperatures of $500^{\circ} \mathrm{C}$ or higher reduced the reaction time, there was a corresponding increase in wax in the final product.

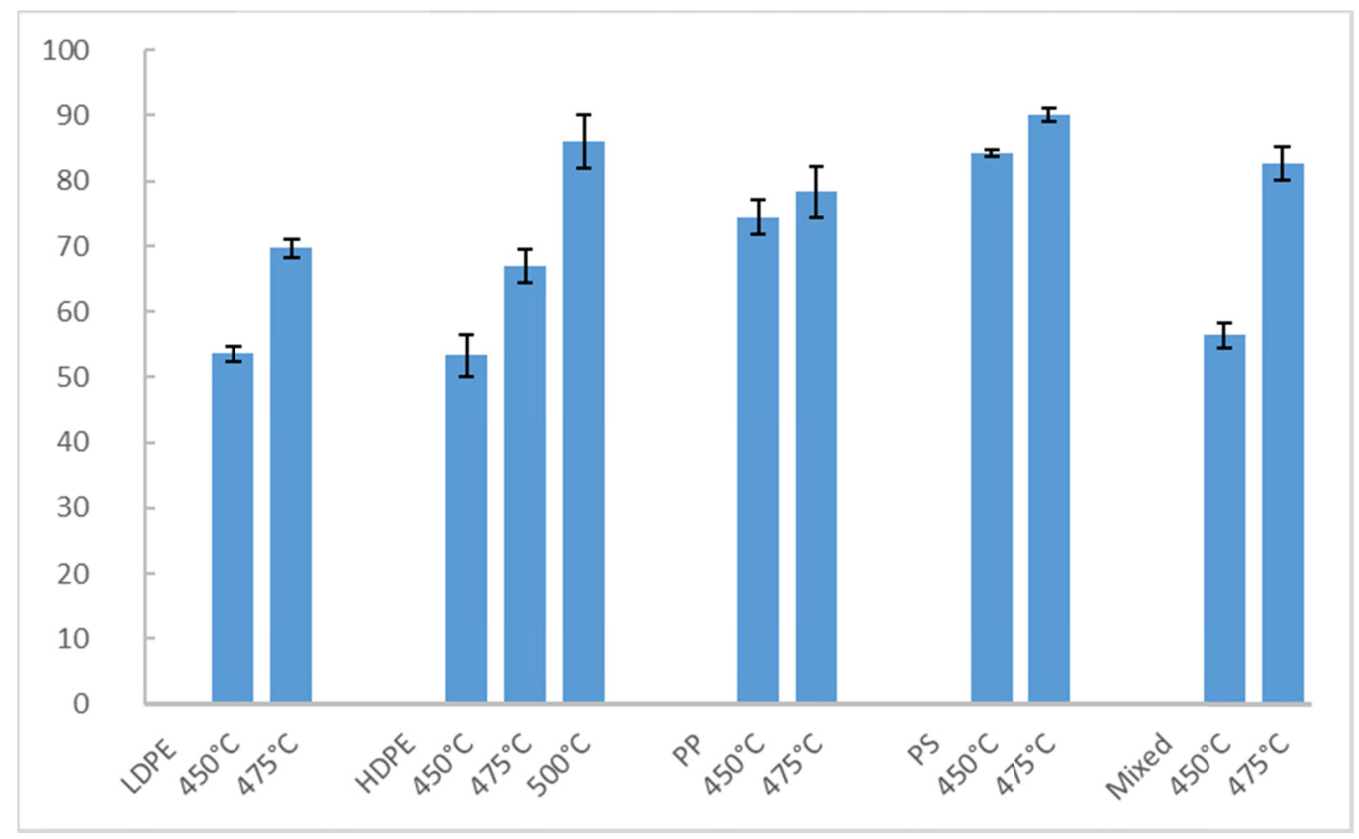

Figure 5. Percent yield versus temperature for various plastic types as well as mixed plastic

\section{Continuous Processor Case Study}

Based on the results of this research, a test batch of fuel oil was produced using a continuous process in Kampala, Uganda. These tests were conducted in collaboration with Makerere University. The continuous process apparatus, illustrated in Figure 6, utilizes an inverted pyramid funnel to allow melted plastic to flow into an air-free chamber where the pyrolysis reaction occurs. The vapor product then flows out of the reaction chamber and is condensed in a water bath. As in the experimental trials, the condensed fuel oil product is collected by decanting. The case study was conducted with mixed plastic consisting of HDPE, LDPE, PP and PS. The process trials were conducted at a constant temperature of $475^{\circ} \mathrm{C}$ using scrap wood as the fuel source for the rocket stove heater. The results indicated that the continuous process based on AT principles was viable outside of the laboratory setting. The continuous processor in use at Makerere University is illustrated in Figure 7. 
2

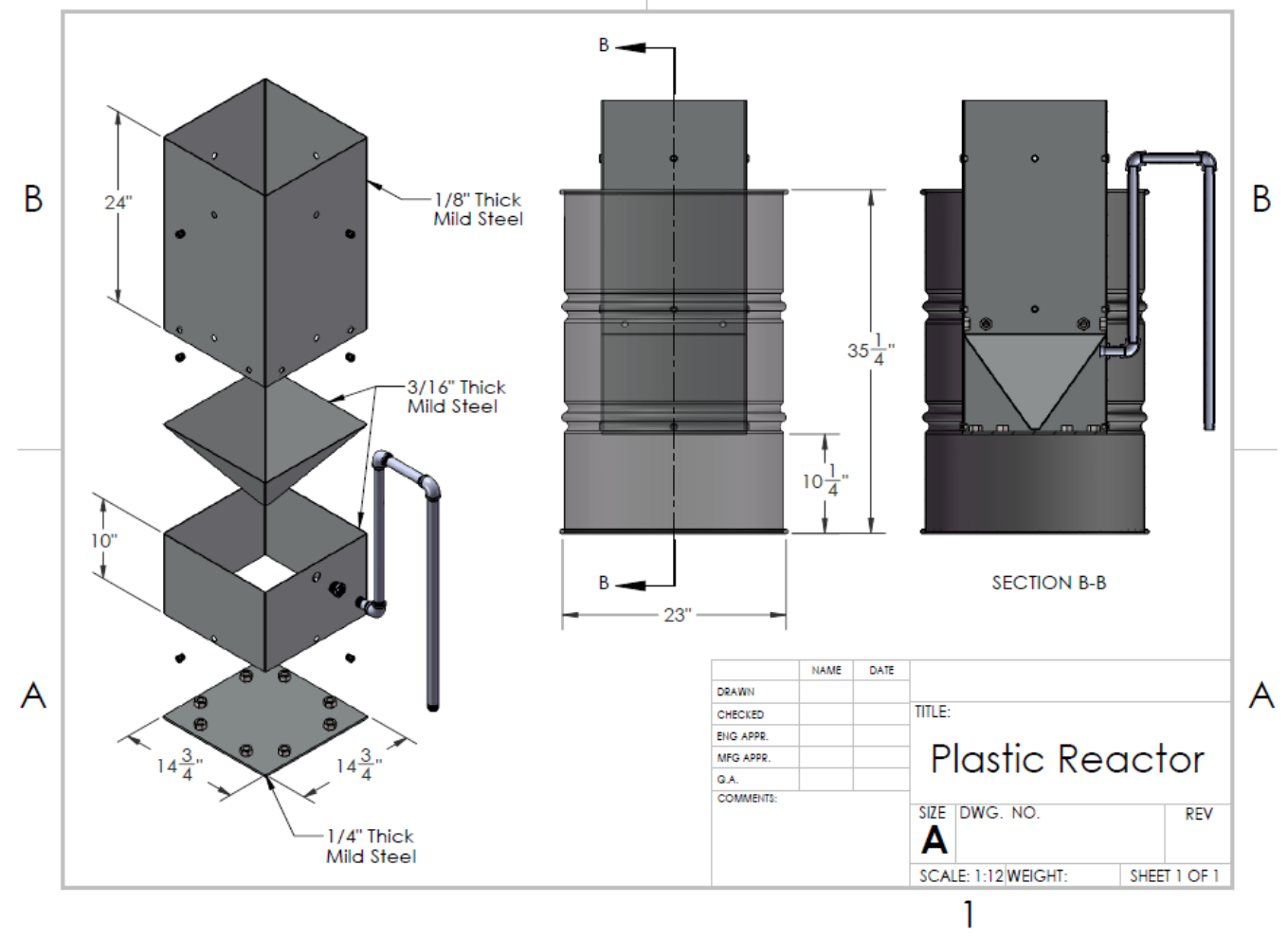

Figure 6. Schematic of AT based continuous waste plastic pyrolysis apparatus

\section{Discussion}

Designing a process based on the principles of AT require that tradeoffs be made (Joshi and Seay, 2016). To maintain a low cost and simple operation, some sacrifices that reduce the yield had to be made. Most importantly, the pyrolysis process was not purged of air prior to the experimental trial. This is due to the fact that in an AT setting, purging is not practical. The presence of air can lead to a loss of yield and an increase in wax formation, although this was found to be minimal. Additionally, the fuel oil was condensed using ambient temperature water. Using chilled water would provide more efficient condensing, but again, this is impractical in an AT based design. Vapor losses ranged from $8 \%$ to $30 \%$ between the experimental trials and published results (Singh and Ruj, 2016).

The results of the field trials in Uganda confirmed that the AT based processor is viable for operation in developing regions. The process produced a fuel oil of sufficient quality for use in either cook stoves for in diesel engines. Although testing is ongoing, this process offers a sustainable solution for the accumulation of waste plastic in developing regions. The UKATS processor is built from low cost materials, which make it affordable for low-income communities. Additionally, since the fuel oil is produced from hydrocarbon plastic, it is sulfur free, which is a benefit to the environment (Joshi and Seay, 2016).

\section{Conclusions and Future Work}

In order to account for the rapid generation of waste plastics in developing countries the UKATS plastic pyrolysis procedure can easily be applied in efforts to begin reducing plastic waste. In most rural applications the controlled plastic sample compositions used for data collection in the laboratory will not be replicable. However, it can be concluded that the optimal temperature can still be used for pyrolysis operation. For optimal fuel oil conversion across all plastic compositions, a heating rate of $20^{\circ} \mathrm{C}$ and a maximum temperature of $475^{\circ} \mathrm{C}$ are appropriate. This temperature will allow significant plastic pyrolysis while following a general assumption that the quality of fuel oil will not change significantly at temperatures surrounding this range. The pyrolysis process can be completed in as little as four hours for this operating temperature, without causing wax formation in the product.

In order to assure successful field application, future work for this process includes additional field testing. Other 
concepts to be researched include a low cost temperature control method for the UKATS processor, total quality analysis of the product fuel oil to address engine fuel applications, completion of mass and energy balances surrounding the UKATS processor and finally the use of other safe and commonly found waste plastics for pyrolysis production, including used tires.

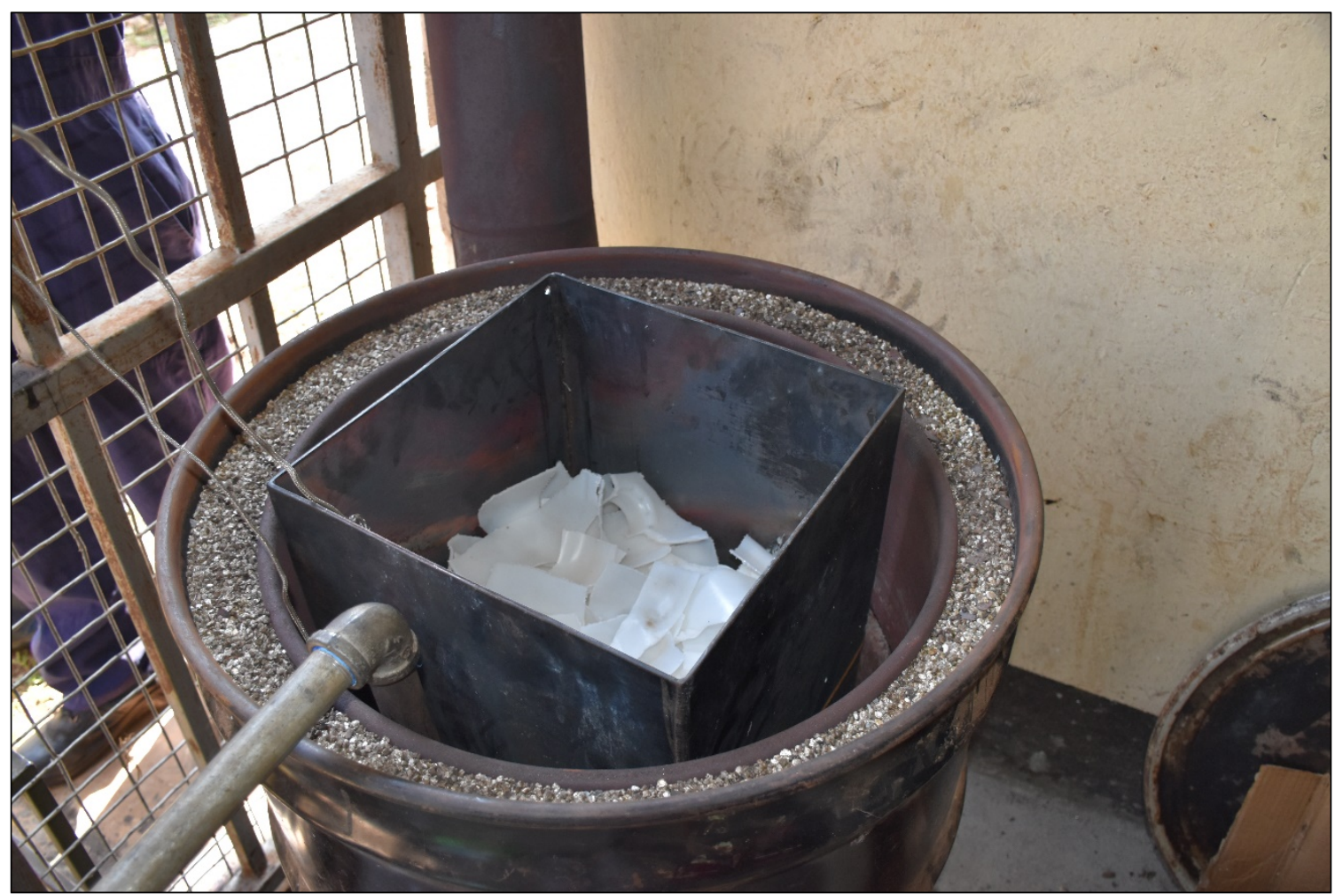

Figure 7. Testing of continuous waste plastic pyrolysis apparatus in Kampala, Uganda

\section{Acknowledgments}

This research was funded in part by a US EPA People, Prosperity and the Planet grant (Award No. SU836115). The authors gratefully acknowledge the assistance of Makerere University, especially Professor Noble Banadda. Finally, the authors acknowledge the generous contributions of DG Home Furnishing for manufacturing the continuous pyrolysis reactor.

\section{References}

Barnes, D. K. A., Galgani, F., Thompson, R. C., \& Barlaz, M. (2009). Accumulation and fragmentation of plastic debris in global environments. Phil. Trans. R. Soc. B, 364, 1985-1998. https://doi.org/10.1098/rstb.2008.0205

Demirbas, A. (2004). Pyrolysis of municipal plastic wastes for recovery of gasoline-range hydrocarbons. Journal of Analytical and Applied Pyrolysis, 72, 97-102. https://doi.org/10.1016/j.jaap.2004.03.001

Green, D. S., Boots, B., Blockley, D. J., Rocha, C., \& Thompson, R. (2015). Impacts of Discarded Plastic Bags on Marine Assemblages and Ecosystem Functioning. Environ. Sci. and Technol., 49, 5380-5389. https://doi.org/10.1021/acs.est.5b00277

Gross, M. (2013). Plastic Waste is All at Sea. Current Biology, 23(4), R135-R137. https://doi.org/10.1016/j.cub.2013.01.070

Hazeltine, B., \& Bull, C. (1999). Appropriate Technology: Tools, Choices, and Implications. New York: Academic Press. pp. 3, 270.

Joshi, C., \& Seay, J. (2016). An Appropriate Technology Based Solution to Convert Waste Plastic into Fuel Oil in Underdeveloped Regions. Journal of Sustainable Development, 9(4). https://doi.org/10.5539/jsd.v9n4p133

Kumar, S., \& Singh, R. K. (2011). Recovery of Hydrocarbon Liquid from Waste High Density Polyethylene by 
Thermal Pyrolysis. Brazilian Journal of Chemical Engineeirng, 28(04), 659-67.

Miskolczi, N., Bartha, L., Deák, G., \& Jóver, B. (2004). Thermal Degradation of Municipal Plastic Waste for Production of Fuel-Like Hydrocarbons. Polymer Degradation and Stability, 86, 357-66. https://doi.org/10.1016/j.polymdegradstab.2004.04.025

Panda, A. K., Singh, R. K., \& Mishra, D. K. (2010). Thermolysis of Waste Plastics to Liquid Fuel. A Suitable Method for Plastic Waste Management and Manufacture of Value Added Products-A World Prospective. Renewable and Sustainable Energy Reviews, 14, 233-48. https://doi.org/10.1016/j.rser.2009.07.005

Pinto, F., Costa, P., Gulyurtlu, I., \& Cabrita, I. (1999). Pyrolysis of Plastic Wastes. 1. Effect of Plastic Waste Composition on Product Yield. Journal of Analytical and Applied Pyrolysis, 51, 39-55. https://doi.org/10.1016/s0165-2370(99)00008-x

Sarker, M., Rashid, M. M., Rahman, M. S., \& Molla, M. (2012a). Production of Valuable Heavy Hydrocarbon Fuel Oil by Thermal Degradation Process of Post-Consumer Municipal Polystyrene (PS) Waste Plastic in Steel Reactor. Energy and Power, 2(5), 89-95. https://doi.org/10.5923/j.ep.20120205.02

Sarker, M., Rashid, M. M., Rahman, M. S., \& Molla, M. (2012b). Conversion of Low Density Polyethylene (LDPE) and Polypropylene (PP) Waste Plastics into Liquid Fuel Using Thermal Cracking Process. British Journal of Environment \& Climate Change, 2(1), 1-11. https://doi.org/10.9734/BJECC/2012/994

Schumacher, E. F. (1973). Small Is Beautiful: Economics as if People Mattered. Harper \& Row, New York, New York.

Sharma, B. K., Moser, B. R., Vermillion, K. E., Doll, K. M., \& Rajagopalan, N. (2014). Production, characterization and fuel properties of alternative diesel fuel from pyrolysis of waste plastic grocery bags. Fuel Processing Technology, 122, 79-90. https://doi.org/10.1016/j.fuproc.2014.01.019

Singh, R. K., \& Ruj, B. (2016). Time and temperature depended fuel gas generation from pyrolysis of real world municipal plastic waste. Fuel, 174, 164-171. https://doi.org/10.1016/j.fuel.2016.01.049

Wong, S. I., Ngadi, N., Abdullah, T. A. T., \& Inuwa, I. M. (2015). Current State and Future Prospects of Plastic Waste as Source of Fuel: A Review. Renewable and Sustainable Energy Reviews, 50, 1167-180. https://doi.org/10.1016/j.rser.2015.04.06

\section{Copyrights}

Copyright for this article is retained by the author(s), with first publication rights granted to the journal.

This is an open-access article distributed under the terms and conditions of the Creative Commons Attribution license (http://creativecommons.org/licenses/by/4.0/). 